\title{
Shock-induced suppression of drinking following electrolytic median raphe lesions
}

\author{
DAVID WIRTSHAFTER and KAREN E. ASIN \\ University of Illinois at Chicago Circle, Chicago, Illinois 60680
}

\begin{abstract}
Electrolytic lesions of the median raphe nucleus in rats were found to attenuate the suppression of drinking produced by noncontingent footshock presented in an environment in which the rats had been trained to drink. Standard passive avoidance of an electrified drinking tube, however, was not altered, demonstrating that, under some circumstances, animals with raphe lesions are capable of showing normal inhibition of a reinforced response. It is suggested that these results may reflect an impairment in the attention paid to less salient aspects of the stimulus environment.
\end{abstract}

Nauta (1958) demonstrated the existence of a rich network of interconnections between forebrain limbic structures and the paramedian tegmentum of the midbrain. In a number of recent studies, it has been demonstrated that electrolytic lesions of the median raphe nucleus, a component of the paramedian tegmental region, produce a number of behavioral effects similar to those seen following hippocampal damage. For example, both limbic and raphe lesions have been shown to increase resistance to extinction in a straight alley (Asin, Wirtshafter, \& Kent, 1979b; Jarrard, Isaacson, \& Wickelgren, 1964), eliminate spontaneous alternation (Asin, Wirtshafter, \& Kent, 1977; Dalland, 1970; Geyer, Puerto, Menkers, Segal, \& Mandell, 1976), impair reversal of T-maze position habits (Asin, Wirtshafter, \& Kent, 1979a; Samuels, 1972), attenuate performance on an 8-arm radial maze task (Olton, Walker, \& Gage, 1978; Wirtshafter, Asin, \& Kent, 1979a), and eliminate latent inhibition in a shuttlebox paradigm (Ackil, Mellgren, Halgren, \& Frommer, 1969; Asin, Wirtshafter, \& Kent, 1979a, 1980; Solomon, Nichols, Kiernan, Kamer, \& Kaplan, 1980). These similarities provide experimental support for Nauta's (1958) concept of a functionally important limbic-midbrain circuit, the existence of which was first postulated on anatomical grounds.

The role of the median raphe in aversively motivated behavior has also been investigated. Median raphe lesions have been reported to impair oneway active avoidance (Srebro \& Lorens, 1975), and similar results have been reported following septal and hippocampal damage (Black, Nadel, \& O'Keefe, 1976; Caplan, 1973; Grossman, 1976). Although combined lesions of the dorsal and median raphe nuclei may improve shuttlebox avoidance (Srebro \&

K. E. Asin's current address: Kinsman Laboratory for Neurological Research, University of British Columbia, 2075 Westbrook Mall, Vancouver, B.C. V6T 1N5, Canada. K.E.A. supported by NINCDS Fellowship 1 F32 NS06399-01.
Lorens, 1975), several authors have reported that lesions confined to the median raphe nucleus fail to have an effect (Asin et al., 1980; Solomon et al., 1980; Srebro \& Lorens, 1975). Plaznik, Kostowski, Bidzinski, and Hauptmann (1980) reported improved shuttlebox avoidance, but their lesions appeared to extend ventrally beyond the bounds of the median raphe nucleus. Median raphe lesions have also been found to impair step-down passive avoidance (Thornton \& Goudie, 1978), but this result may be difficult to interpret in view of the well-known hyperactivity of animals with median raphe lesions (Asin et al., 1979b; Geyer et al., 1976; Jacobs \& Cohen, 1976; Srebro \& Lorens, 1975).

In the current study, we investigated the effects of electrolytic median raphe lesions on shockinduced suppression of a drinking response. Use of a drinking response seems advantageous in that, as demonstrated below, raphe lesions alter neither the latency to drink nor the amount of water consumed following deprivation. The ability of both responsecontingent and noncontingent shock to suppress drinking was examined.

\section{EXPERIMENT 1}

\section{Method}

Subjects. Eleven male Sprague-Dawley-derived rats, obtained from a colony maintained by the University of Illinois, were used as subjects. The rats weighed about $300 \mathrm{~g}$ at the time of surgery. The animals were housed in individual wire-mesh cages with a 12:12 h light-dark cycle in effect. Food and water were available ad lib except for the training period, as described below. Five randomly selected animals received raphe lesions, and the remainder were sham operated.

Surgery. Surgery was performed under sodium pentobarbital anesthesia $(50 \mathrm{mg} / \mathrm{kg})$. A stainless steel electrode, $.23 \mathrm{~mm}$ in diameter and insulated except for $.5 \mathrm{~mm}$ at the tip, was stereotaxically placed (Pellegrino \& Cushman, 1967) at coordinates AP, -0.2 ; Lat, $0.0 ; \mathrm{H},-4.3$. The electrode was lowered in the sagittal plane following retraction of the superior sagittal sinus as described by Wirtshafter, Asin, and Kent (1979b). A 1-mA current was then passed for $8 \mathrm{sec}$ between the electrode and a rectal 
cathode. In sham-operated animals, a burr hole was drilled and the dura opened, but the electrode was not lowered.

Apparatus. Drinking was examined in a standard Lehigh Valley operant box (Model 143-26) from which the levers had been removed and into which a graduated drinking had been inserted. A scrambled footshock $(140 \mathrm{~V})$ was supplied by a Hunter shock source (Model 350) with an internal impedance of $18.2 \mathrm{k} \Omega$ in series with a Lehigh Valley shock scrambler (Model 779). The animals were run in a darkened room with light provided by a neon desk lamp directed towards the interior of the operant chamber. A masking noise of $55 \mathrm{~dB}$ was provided by the operation of the shock scrambler.

Procedure. Training was begun at least 30 days following surgery. The water bottles were removed from the animals' home cages, and $23.5 \mathrm{~h}$ later the rats were placed in the operant chamber and allowed to drink for $15 \mathrm{~min}$. Latency to begin drinking was measured to the nearest second and amount drunk to the nearest millimeter. The animals were then returned to their home cages and allowed to drink for a further $15 \mathrm{~min}$, at the end of which their water bottles were again removed. An identical approach training session was given on the next day. On Day 3, the animals were placed in the operant box with the tube withdrawn and, 2 min later, were shocked for $30 \mathrm{sec}$. The animals were removed from the operant chamber $2 \mathrm{~min}$ later and returned to their home cages where they were allowed to drink for $15 \mathrm{~min}$. On each of Days 4-7, the animals were allowed to drink for $15 \mathrm{~min}$ in the operant chambers followed by $15 \mathrm{~min}$ in their home cages. No shock was presented during this period.

Histology. Following the completion of behavioral studies, the rats were given an overdose of sodium pentobarbital and were perfused intracardially with normal saline followed by $10 \%$ Formalin. Brains were removed from the skull at once and stored in Formalin for a minimum of 2 weeks. Sixty-four-micron-thick frozen sections were made through the extent of the lesion and were photographed unstained.

\section{Results}

Latency to begin drinking and amount drunk did not differ between lesioned and sham-operated animals during the 2 days of pretraining. Latencies to drink on the 4 days following shock are shown in Figure 1 . It can be seen that the animals with median

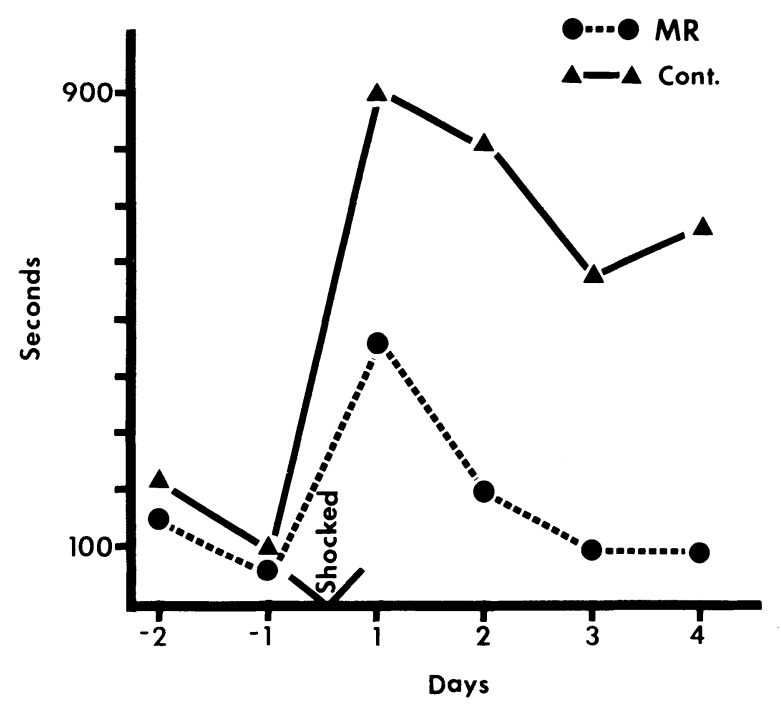

Figure 1. Mean latencies to drink for animals with median raphe lesions (MR) and sham-operated controls (Cont.) on the 2 days before and the 4 days following shock administered in the drinking chamber. Experiment 1.

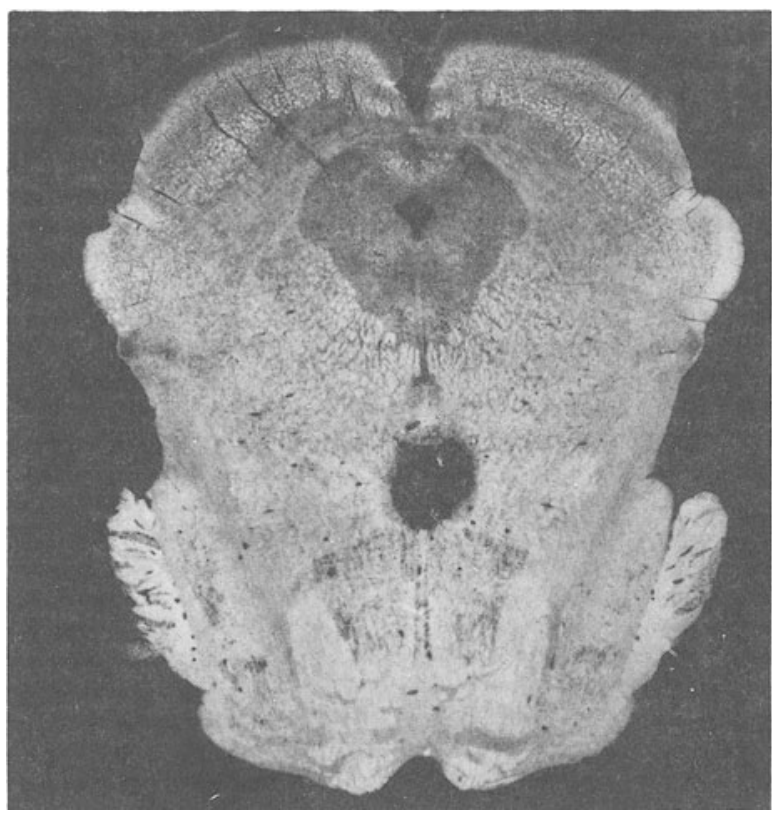

Figure 2. A photograph of an unstained section through the maximal extent of a typical median raphe lesion. Magnification equals $10 x$.

raphe lesions showed a much smaller suppression of drinking in response to shock than did sham-operated animals. This conclusion is supported by the results of a $2 \times 4$ (lesion $\times$ days) repeated measures factorial analysis of variance, which demonstrated significant effects of median raphe lesions $[F(1,9)=22.8, p<$ $.001]$ and of days $[F(3,27)=5.38, p<.05]$. The lesion $\times$ days interaction, however, did not approach significance $(F<1)$. Analysis of amounts drunk indicated a significant effect of raphe lesions $[F(1,9)=$ $12.54, \mathrm{p}<.01$ ] but not of time.

A photograph of a section through the greatest extent of a typical median raphe lesion is shown in Figure 2. In all cases, the median raphe nucleus was severely damaged. Occasional minor damage to the ventral tegmental nuclei of Gudden or the nuclei reticularis tegmenti pontis was observed in some rats, but this did not appear to correlate with any behavior studied.

\section{Discussion}

This experiment demonstrates that electrolytic lesions of the median raphe nucleus reduce the suppression of drinking produced by shock that is uncorrelated with the drinking response. The procedure employed in this study would appear formally to be a variant of the conditioned emotional response paradigm, with the testing chamber itself serving as the conditioned stimulus. It seems unlikely that this effect of raphe damage results from alterations in drinking behavior per se, since baseline intakes and latencies did not differ between lesioned and control groups. It is possible that animals with raphe 
lesions drank less in their home cages than controls and were thus thirstier on the first day of testing. This possibility seems unlikely however, since, in another group of rats which received identical pretraining, home cage drinking following shock did not differ between experimental and control subjects (Wirtshafter \& Asin, Note 1).

\section{EXPERIMENT 2}

In this experiment, we examined the effects of median raphe lesions on a conventional passive avoidance task in which individual licks were punished.

\section{Method}

Subjects and Surgery. The subjects were 10 rats similar to those described in Experiment 1. Five of the animals received median raphe lesions and five were sham operated. The surgical procedure was identical to that described for Experiment 1.

Apparatus. Testing was performed in the operant chamber used in the first experiment. A Hunter shock source was connected to the box in such a fashion that, with each lick, the rat completed a circuit between the drinking tube and the grid floor of the operant box. The shock source produced a potential of $50 \mathrm{~V}$ through an impedance of $29 \mathrm{k} \Omega$.

Procedure. At least 30 days following surgery, the rats were given 2 days of approach training, as in the first experiment. On Day 3, they were allowed to drink for 2 min following the onset of licking, at which time the drinking tube was electrified. The rats were allowed to remain in the chamber for $15 \mathrm{~min}$ and the number of contacts with the drinking tube were recorded.

\section{Results}

The rats with median raphe lesions and the shamoperated animals showed almost identical latencies to drink and amounts consumed in the 2 days of approach training. On Day 3, with the drinking tube electrified, the controls made an average of $8.4 \pm .6$ and raphes $9.1 \pm .8$ contacts with the drinking tube $(p>.25)$.

\section{Discussion}

The results of this experiment suggest that median raphe lesions do not impair the passive avoidance of an electrified drinking tube. Although numbers of tube contacts did not differ between groups, the general behavior of the animals appeared to. Thus, control animals spent most of their time "freezing", in the corner of the operant box farthest from the drinking tube, whereas subjects with raphe lesions remained active throughout the session, merely avoiding licking at the tube.

\section{EXPERIMENT 3}

In order to examine the generality of the results of Experiment 2, we examined passive avoidance in another group of animals using slightly different testing conditions. Four days of pretraining were employed and a slightly higher shock intensity was used than in the previous experiment, since these variables are known to play an important role in the appearance of passive avoidance deficits following septal lesions (Middaugh \& Lubar, 1970). Additionally, open-field activity was measured in order to confirm that the raphe lesions examined here produced as much hyperactivity as we had observed in previous studies.

\section{Method}

Subjects. Ten rats, similar to those described above, were used. Five rats received raphe lesions and five were sham operated.

Apparatus. Drinking was measured in an operant chamber identical to that used in the previous experiment. Activity was measured in a $152.5 \times 91.5 \mathrm{~cm}$ open field enclosed by $47-\mathrm{cm}$-high plywood walls. The floor of the field was divided into $1530.5 \times$ $30.5 \mathrm{~cm}$ squares. Lighting was provided by overhead fluorescent fixtures.

Procedure. Open-field activity was measured 2 weeks following surgery. The rats were gently placed in the middle of the field, and the number of squares entered and the number of fecal boli deposited were recorded over a 5-min period. A rat was considered to have entered a square when all four paws were placed in it.

Passive avoidance training began about 30 days following surgery. The rats received 4 days of approach training identical to that of the previous experiments. The procedure on the first day of avoidance training was identical to that of Experiment 2 except that a shock of $67 \mathrm{~V}$ was applied through an impedance of $26 \mathrm{k} \Omega$. Following this session, the rats were allowed to drink for $15 \mathrm{~min}$ in their home cages, and intake during this time was measured to the nearest milliliter. Twenty-three hours later, the rats were again placed in the operant chamber with the avoidance contingency in effect from the beginning of the session.

\section{Results}

During the $5 \mathrm{~min}$ of testing in the open field, the controls entered a mean of $37.0 \pm 5.1$ squares and the animals with raphe lesions entered $131 \pm 7.9$ squares $[t(8)=9.93, p<.001]$. Number of defecations did not differ between groups.

As in the previous experiments, latency to drink and amount consumed did not differ between experimental and control subjects during approach training. Table 1 displays the number of punished licks by. raphe-damaged and control animals on the 2 days of passive avoidance testing. A $2 \times 2$ (lesion $\times$ days) repeated measures analysis of variance indicated a significant effect of days $[F(1,6)=13.0, p<.02]$, but

\section{Table 1}

Passive Avoidance Performance of Median Raphe-Lesioned and Sham-Operated Control Rats on the 2 Days of Testing in Experiment 3

\begin{tabular}{lccccc}
\hline & \multicolumn{2}{c}{ No. of Punished Licks } & & \multicolumn{2}{c}{ Latency to Drink } \\
\cline { 2 - 3 } & Day 1 & Day 2 & & Day 1 & Day 2 \\
\hline SO & $5.2 \pm 0.6$ & $3.0 \pm 0.8$ & $31.0 \pm 16.5$ & $23.0 \pm 9.2$ \\
MRL & $6.5 \pm 1.2$ & $2.0 \pm 0.6$ & $41.2 \pm 12.5$ & $14.0 \pm 5.4$ \\
\hline
\end{tabular}

Note-SO = Sham operated. $M R L=$ Median raphe lesioned. 
not of raphe lesions $(F<1)$. The lesion $x$ days interaction also failed to reach significance $(p>.25)$. Animals in both groups drank almost identical amounts in their home cages following the first avoidance session. Latencies to the first lick on the second day of passive avoidance training did not differ between groups, and neither group showed a trend toward increased latencies relative to their baselines. Pooling raphe and control subjects together, it can be demonstrated that fewer licks were made on the first day of avoidance training in the current experiment than were in Experiment $2[\mathrm{t}(18)=2.3, \mathrm{p}<.05]$, presumably as a result of the higher shock level employed.

\section{Discussion}

In agreement with a number of previous reports (see introduction), this experiment demonstrates that raphe lesions result in a very pronounced open-field hyperactivity. The magnitude of this effect in the current experiment was quite similar to what we had observed previously (Asin et al., 1979). Amount of defecation, however, was not altered, which is also in accord with findings in the literature (Geyer et al., 1976; Srebro \& Lorens, 1975). In spite of their hyperactivity, rats with raphe lesions showed passive avoidance behavior almost identical to that of controls on both Days 1 and 2 of testing. The animals with lesions, furthermore, showed 24-h retention of the response similar to that of the controls, as evidenced by the failure of the lesion $\times$ days interaction to reach significance.

\section{GENERAL DISCUSSION}

The results of the first experiment demonstrate that median raphe lesions reduce the suppression of drinking produced by noncontingent footshock. The exact procedure employed in this study has, to our knowledge, not been previously used to study the effects of brain lesions. However, damage to a number of structures, including the hippocampus (Brady \& Hunt, 1955), septum (Brady \& Hunt, 1955; Harvey, Lints, Jacobson, \& Hunt, 1965; Trafton, 1967), and habenula (Brady \& Nauta, 1955) has been shown to reduce the conditioned emotional response produced by the pairing of shock with a discrete conditioned stimulus. As noted above, the procedure used in Experiment 1 is formally identical to that used in typical CER experiments, except that the operant chamber itself served as the conditioned stimulus.

The results of Experiments 2 and 3 suggest that median raphe lesions do not impair the suppression of drinking produced by electrifying the drinking tube. Although it is certainly possible that selection of different shock and pretraining parameters would have allowed the demonstration of a deficit, this possibility is rendered less likely by our failure to observe an effect under two different testing conditions.
Additionally, using a paradigm very similar to that of Experiment 2, we have been able to detect impairments in passive avoidance following lesions of the interpeduncular nucleus (Wirtshafter, 1981).

In comparing the effects of raphe lesions with those of other brain areas, it should be noted that, although avoidance of an electrified drinking tube is usually impaired following septal damage (Caplan, 1973; Grossman, 1976), hippocampal lesions appear to be without effect (Black et al., 1976). As noted in the introduction, the behavioral syndromes produced by median raphe and hippocampal damage appear, in general, to be very similar, and both anatomical (Bobillier, Seguin, Petijean, Salvert, Touret, \& Jouvet, 1976; Conrad, Leonard, \& Pfaff, 1974; Nauta, 1958) and electrophysiological (Winson, 1977; Yamamoto, Watanabe, Oishi, \& Veki, 1979) evidence provides further support for the notion of a functional relation between these structures.

The impairments seen in the first experiment could be the result of at least three different sorts of deficits: (1) an inability to suppress prepotent behavior patterns, (2) a reduction in "fear," or (3) an impairment in associating shock with the stimulus cues of the drinking box. The first of these explanations, a "general inhibitory deficit," would have the advantage of accounting for both the present results and for the impairments in extinction (Asin et al., 1978) and reversal learning (Asin et al., 1979a) seen following median raphe lesions. The finding that these lesions do not impair avoidance of an electrified drinking tube, however, demonstrates that, under some circumstances, animals with median raphe lesions are capable of suppressing ongoing behavior, and this fact casts doubt on the generality of this hypothesis.

A deficit in "fear" could also explain the results of the first experiment. Decreased "fear" would also be expected to produce impairments in one-way active avoidance, and this deficit has in fact been reported following raphe lesions (Srebro \& Lorens, 1975). The reduced-fearfulness hypothesis would, however, encounter some difficulties in accounting for the results of Experiments 2 and 3, although one might postulate that mechanisms other than "fear" are involved in the suppression of a particular behavior paired with shock.

The results obtained here might also reflect an impaired ability of animals with raphe lesions to associate shock with apparatus cues. We have suggested elsewhere that animals with raphe damage may pay less attention to environmental stimuli, unless they are highly salient, than do controls (Asin et al., 1980; Wirtshafter et al., 1980). It seems likely that stimuli associated with the drinking spout, to which the rat actively responds, would be more salient than other background cues associated with the testing environment. Were these assumptions correct, one might ex- 
pect that animals with raphe lesions would be less impaired in associating shock with the drinking tube than with the apparatus. This attentional hypothesis has the advantage of being able to account for many of the effects of median raphe lesions on tasks not involving negative reinforcement (Asin et al., 1980; Wirtshafter et al., 1980).

Finally, it should be noted that since electrolytic median raphe lesions undoubtedly damage both serotonergic and nonserotonergic elements (Aghajanian \& Asher, 1971; Lorens, Kohler, \& Goldberg, 1975), it should not be concluded that the effects reported here necessarily reflect serotonin depletion. Conversely, since the median raphe nucleus is not the sole source of brain serotonin, it should not be concluded that the behavioral effects of pharmacological depletion of serotonin necessarily result from serotonin depletion in regions supplied by the median raphe nucleus. For example, Stevens and Fechter (1969) reported that injections of p-chlorophenylalanine impaired avoidance of an electrified drinking tube, but this result might be due to disruption of serotonergic systems originating in other structures, such as the dorsal raphe nucleus (cf. Stein, Wise, \& Belluzzi, 1973; Telgedy, Kovacs, \& Vermes, 1978).

\section{REFERENCES NOTE}

1. Wirtshafter, D., \& Asin, K. E. Unpublished observations, 1979.

\section{REFERENCES}

Ackil, J. E., Mellgren, R. L., Halgren, C., \& Frommer, G. P. Effects of CS preexposures on avoidance learning in rats with hippocampal lesions. Journal of Comparative and Physiological Psychology, 1969, 69, 739-747.

Aghajanian, G. K., \& Asher, I. M. Histochemical fluorescence of raphe neurons: Selective enhancement by tryptophan. Science, 1971, 172, 1159-1161.

Asin, K. E., Wirtshafter, D., \& Kent, E. W. An investigation of the role of the medial nucleus of the raphe in behavior. Society for Neuroscience Abstracts, 1977, 3, 245.

Asin, K. E., Wirtshafter, D., \& Kent, E. W. Behavioral effects of lesions of the median nucleus of the raphe. Society for Neuroscience Abstracts, 1978, 4, 267.

Asin, K. E., Wirtshafter, D., \& Kent, E. W. Discrimination learning and reversal following electrolytic median raphe lesions. Society for Neuroscience Abstracts, 1979, 5, 269. (a)

Asin, K. E., Wirtshafter, D., \& Kent, E. W. Straight alley acquisition and extinction and open field activity following discrete electrolytic lesions of the mesencephalic raphe nuclei. Behavioral and Neural Biology, 1979, 25, 242-256. (b)

Asin, K. E., Wirtshafter, D., \& Kent, E. W. The effects of electrolytic median raphe lesions on two measures of latent inhibition. Behavioral and Neural Biology, 1980, 28, 408-417.

Black, A. H., Nadel, L., \& O'KeEFe, J. Hippocampal function in avoidance learning and punishment. Psychological Bulletin, 1976, 84, 1107-1129.

Bobillier, P., Seguin, S., Petijean, F., Salvert, D., Touret, M., \& Jouvet, M. The raphe nuclei of the brain stem: A topographical atlas of their efferent projections as revealed by autoradiography. Brain Research, 1976, 113, 449-486.
Brady, J. V., \& Hunt, H. F. An experimental approach to the analysis of emotional behavior. Journal of Psychology, 1955, 40, 313-324.

Brady, J. V., \& NaUta, W. J. H. Subcortical mechanisms in emotional behavior: The duration of affective changes following septal and habenular lesions in the albino rat. Journal of Comparative and Physiological Psychology, 1955, 48, 412-420.

Caplan, M. An analysis of the effects of septal lesions on negatively reinforced behavior. Behavioral Biology, 1973, 9, 129-169.

Conrad, L. C., Leonard, C., \& Pfaff, D. Connections of the median and dorsal raphe nuclei in the rat: An autoradiographic and degeneration study. Journal of Comparative Neurology, 1974, 156, 179-206.

Dalland, T. Response and stimulus perseveration in rats with septal and dorsal hippocampal lesions. Journal of Comparative and Physiological Psychology, 1970, 71, 114-118.

Geyer, M. A., Puerto, A., Menkers, D., Segal, D. S., \& Mandell, A. J. Behavioral studies following lesions of the mesolimbic and mesostriatal serotonergic pathways. Brain Research, 1976, 106, 257-270.

Grossman, S. P. Behavioral functions of the septum: A reanalysis. In J. F. DeFrance (Ed.), The septal nuclei. New York: Plenum Press, 1976.

Harvey, J. A., Lints, C. E., Jacobson, L. W., \& Hunt, H. F. Effects of lesions in the septal area on conditioned fear and discriminated instrumental punishment in the albino rat. Journal of Comparative and Physiological Psychology, 1965, 59, 37-48.

J ACOBS, B. L., \& Cohen, A. Differential behavioral effects of lesions of the median or dorsal nuclei in rats: Open field and pain elicited aggression. Journal of Comparative and Physiological Psychology, 1976, 90, 102-108.

Jarrard, L. E., IsaAcson, R. L., \& Wickelgren, W. D. Effects of hippocampal ablation and intertrial interval on runway acquisition and extinction. Journal of Comparative and Physiological Psychology, 1964, 57, 442-444.

Lorens, S. A., Kohler, C., \& Goldberg, H. C. Lesions in Gudden's tegmental nuclei produce behavioral and 5-HT effects similar to those after raphe lesions. Pharmacology, Biochemistry and Behavior, 1975, 3, 653-659.

Middaugh, L. D., \& Lubar, J. F. Interaction of septal lesions and experience on the suppression of punished responses. Physiology \& Behavior, 1970, 5, 233-238.

NAUTA, W. J. H. Hippocampal projections and related neural pathways to the midbrain in the cat. Brain, 1958, 81, 319-340.

Olton, D. S., W Alker, J. A., \& Gage, F. H. Hippocampal connections and spatial discrimination. Brain Research, 1978, 13, 295-308.

Pellegrino, L. J., \& Cushman, A. J. A stereotaxic atlas of the rat brain. New York: Appleton-Century-Crofts, 1967.

Plaznik, A., Kostowski, W., Bidzinski, A., \& Hauptmann, M. Effects of lesions of the midbrain raphe nuclei on avoidance learning in rats. Physiology \& Behavior, 1980, 24, 257-262.

SAmuels, I. Hippocampal lesions in the rat: Effects on spatial and visual habits. Physiology \& Behavior, 1972, 8, 1093-1098.

Solomon, P. R., Nichols, G. L., Kiernan, J. M., Kamer, R. S., \& Kaplan, L. J. Differential effects of lesions in medial and dorsal raphe of the rat: Latent inhibition and septohippocampal serotonin levels. Journal of Comparative and Physiological Psychology, 1980, 94, 145-163.

Srebro, B., \& Lorens, S. A. Behavioral effects of selective midbrain raphe lesions in the rat. Brain Research, 1975, 89, 303-325.

STEin, L., Wise, C. D., \& Belluzi, J. Effects of benzodiazepines on central serotonergic mechanisms. In E. Costa \& P. Greengard (Eds.), Mechanism of action of the benzodiazepines. New York: Raven Press, 1973.

Stevens, D. A., Fechter, L. D., \& Resnick, O. The effects of p-chlorophenylalanine, a depletor of brain serotonin, on behavior: II. Retardation of passive avoidance learning. Life Sciences, 1969, 8, 379-385.

Telgedy, G., Kovacs, G. L., \& Vermes, I. Action of corticosteroid on brain serotonin metabolism in correlation with avoid- 
ance behavior in rats. In $\mathrm{K}$. Lissak (Ed.), Neural and neurohumoral organization of motivated behavior. Budapest: Akedemia Kiado, 1978.

Thornton, E. W., \& Goudie, A. J. Evidence for the role of serotonin in the inhibition of specific motor responses. Psychopharmacology, 1978, 60, 73-79.

Trafton, C. L. Effects of lesions in the septal area and cingulate cortical areas on conditioned suppression of activity and avoidance behavior in rats. Journal of Comparative and Physiological Psychology, 1967, 63, 191-197.

Winson, J. Effect of median raphe stimulation on neuronal transmission through the dentate gyrus in the freely moving and anesthetized rat. Society for Neuroscience Abstracts, 1977, 3, 208.

Wirtshafter, D. Role of interpeduncular connections with the tegmentum in avoidance learning. Physiology \& Behavior, 1981, 26, 985-989.
Wirtshafter, D., Asin, K. E., \& Kent, E. W. Median raphe lesions impair the acquisition and performance of an 8-arm maze task. Society for Neuroscience Abstracts, 1979, 5, 285. (a)

Wirtshafter, D., Asin, K. E., \& Kent, E. W. A simple technique for midline stereotaxic surgery in the rat. Physiology \& Behavior, 1979, 23, 409-410. (b)

Wirtshafter, D., Asin, K. E., \& Kent, E. W. An analysis of open field hyperactivity following electrolytic median raphe lesions in the rat. Society for Neuroscience Abstracts, 1980, 6, 422.

Yamamoto, T., Watanabe, S., Oishi, R., \& Veki, S. Effects of midbrain raphe stimulation and lesion on EEG activity in rats. Brain Research Bulletin, 1979, 4, 491-495.

(Manuscript received November 10, 1980; revision accepted for publication June 16,1981 .) 